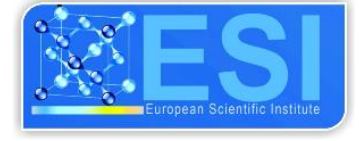

10 years ESJ

Special edition

\section{N. Fernando}

University of Colombo, Sri Lanka

\section{A. Senanayake}

University of Colombo, Sri Lanka

D. Amaratunga

University of Huddersfield, UK

\section{R. Haigh}

University of Huddersfield, UK

\section{Malalgoda}

University of Huddersfield, UK

\section{R.R.J.C Jayakody}

University of Huddersfield, UK

Submitted: 31 August 2020

Accepted: 17 November 2020

Published: 31 December 2020

Corresponding author:

Nishara Fernando

DOI: $\underline{10.19044 / \text { esj.2020.v16n39p33 }}$

(c) Copyright 2020 Fernando, N. et al. Distributed under Creative Commons BY-NC-ND 4.0 OPEN ACCESS

\section{Impact of the disaster-induced relocation process on the displaced communities in Kegalle district, Sri Lanka}

\section{Abstract}

Disaster induced displacement and relocation is a frequently occurring phenomenon in the Sri Lankan context. Resettlement has been recognized as a regular result of disasters such as landslides due to the large-scale property damage that occurs. This paper investigates the impact of the disasterinduced relocation process on displaced communities. The study revolves around the sub-objectives of investigating the various needs of victims in different stages of displacement and how relocation has altered the social, cultural, and livelihood dimensions of the victims. Victims of the Aranayake landslide who were residing in the Kegalle district and who were resettled mainly in a Donor Driven relocation site were selected for the study. A purposive sampling technique was implemented in two phases. In the first phase, in-depth interviews with officials and focus group interviews with community members were carried out. Next, a community needs analysis was conducted with the participation of the community and officials. The data suggests that there is a clear lacuna in strong, written policy frameworks and its practical implementation when satisfying the various needs of displaced communities. Being confined to only understanding the social and economic details of various displaced groups, policy planners have tended to neglect the necessity of conducting a needs analysis with the main reason being the lack of perception of relocation as a long-term process. Therefore, in conclusion, the study suggests a model that addresses the need for a holistic institutional arrangement with further disaster risk management strategies to address the

Cite as:

Fernando N. et al. (2020). Impact of the disaster-induced relocation process on the displaced communities in Kegalle district, Sri Lanka. European Scientific Journal, ESJ, 16(39), 33. https://doi.org/10.19044/esj.2020.v16n39p33 
adverse impact on the disaster-induced, displaced community. relocations, community needs, built environment

Keywords: disasters, displacement,

\section{Introduction}

Having being ranked $63^{\text {rd }}$ in the World Risk Report (2017) on natural disaster risk-driven vulnerability, Sri Lanka is undoubtedly disaster-prone. According to statistics of recent years, it is stated that from $1^{\text {st }}$ January to 31 st December 2017, a total of 135,000 people were displaced due to the high incidence of natural hazards (International Displacement Monitoring Centre- Sri Lanka, 2017).

According to the National Disaster Relief Service Centre (2018), 49, 364 families and 188,328 individuals have been affected by floods and landslides in 2018. It further reports that 186 houses were entirely damaged and 551 infrastructural facilities were affected due to the said hazards. Table 1 summarizes the disaster risk profile of Sri Lanka with the districts which are most vulnerable to floods and landslides.

Table 1: Districts affected by floods and landslides in 2018

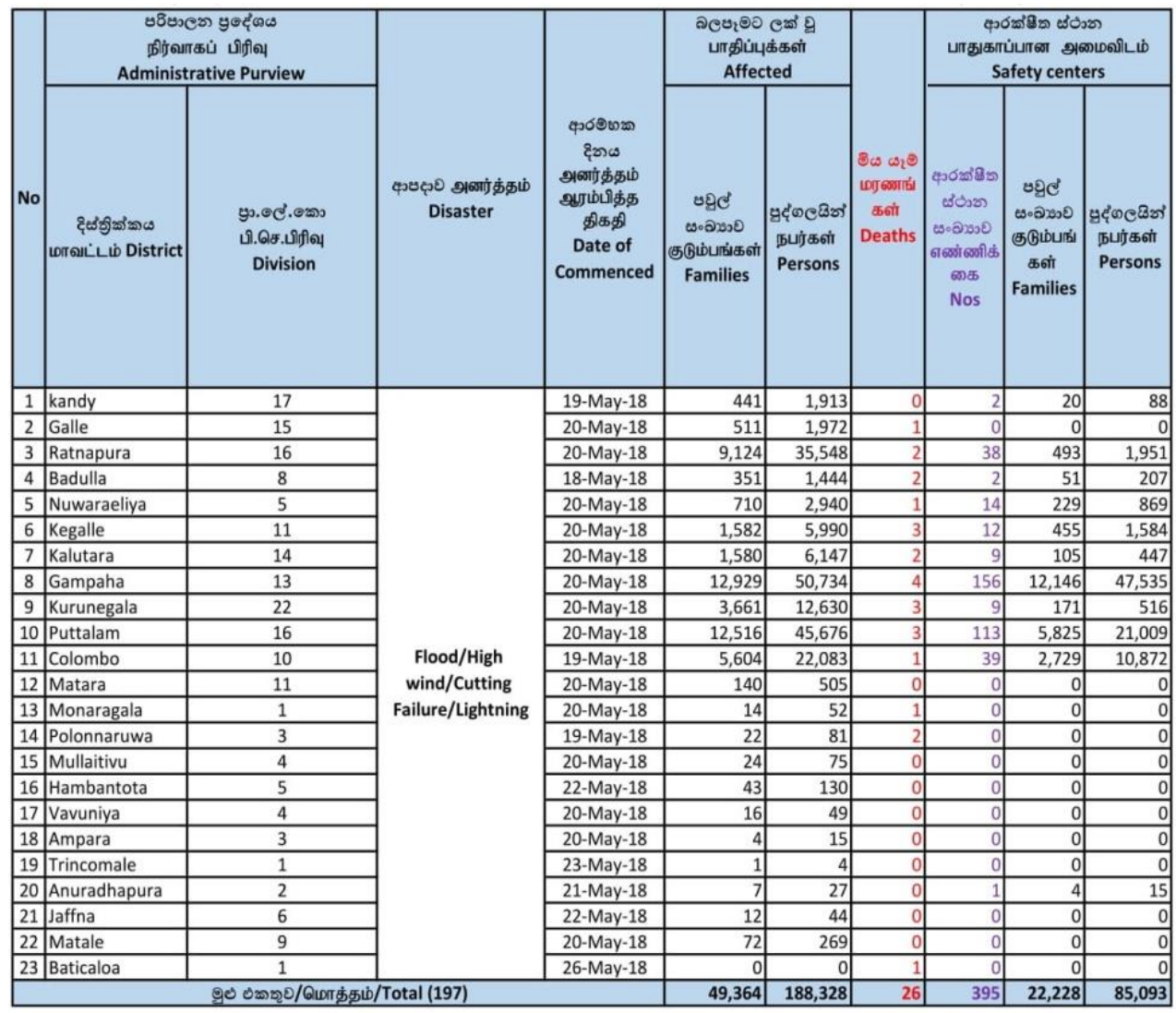

(Source: National Disaster Relief Service Centre, 2018) 
Out of these districts, Kandy, Kurunagala, and Kegalle can also be identified as hazard-prone areas which have not been subject to research on disaster-induced displacement and resettlement in Sri Lanka, despite being affected continuously for decades.

As mentioned before, 49, 364 families have been affected by floods and landslides in 2018 in Sri Lanka while Kegalle was one of the top ten disaster-prone areas in Sri Lanka. Out of 49, 364 families, 1582 have been reported from Kegalle. The National Disaster Relief Service Centre (2018) further reports that 1582 families and 5990 individuals were affected due to flooding and landslides in 2018. It also points out that 950 housing units were partially damaged and 6 were fully damaged during the 2018 floods and landslides.

Kegalle is a district with 11 DS Divisions and has been facing multiple hazard impacts throughout the years. The statistics of the district depicts that it is one of the most vulnerable districts in Sri Lanka which is constantly exposed to floods and landslides related displacement. In May 2016, heavy rainfall triggered flooding and landslides in 15 districts of Sri Lanka, displacing more than 630,000 individuals and causing further deaths and various other socio-economic effects on the victims (International Displacement Monitoring Centre, 2018). The Samasarakanda mountain is situated in the mountainous Aranayaka Divisional Secretariat Divison (DSD) of the Kegalle District in the Sabaragamuwa Province. It was one of the worst landslides that were experienced in the region. The landslide was triggered by unexpected severe rainfall of about $300-400 \mathrm{~mm}$ which occurred in the region from $15^{\text {th }}$ to $19^{\text {th }}$ of May 2016. This was a result of a tropical depression (low-pressure area) that closely passed Sri Lanka from the south to the north (Sangasumana, 2018).

It is against the above background that this paper attempts to achieve the following main and sub-objectives.

\section{Aim, Objectives and Methods of the study}

The aim of this study is to investigate the impact of the disasterinduced relocation process on the displaced communities; the following objectives were addressed to achieve the aim of the study:

1. To explore various needs of victims in different stages of relocation

2. To examine how relocation has altered the social, cultural and livelihood dimensions of the said needs of the victims

3. To understand the role of the built environment in the relocation process 
To achieve the objectives of the study, both primary and secondary data were collected using a cross-sectional study design. The study was conducted for a period of ten months (from March to December) in the year 2019. As it has already been mentioned, the present paper focuses on disaster-induced relocation in the Kegalle district. At present, there are 7 on-going resettlement sites managed by the National Building Research Organization [NBRO], Sri Lanka in the Kegalle district. The reconstruction sites in the area can be identified as both owner-driven and donor-driven which will further be elaborated in the section on findings:

Table 2: Number of Donour Driven sites in Kegalle

\begin{tabular}{|l|l|}
\hline Resettlement site & GN Division \\
\hline Wasanthagama & Narangammana \\
\hline China friendship house & Ruwandeniya \\
\hline Debathgamawatta & Kalugala \\
\hline Panawatta & Meegasthenna \\
\hline Kalupahana & Udapotha \\
\hline Ilukthenna & Wattegedara \\
\hline
\end{tabular}

(Source: Field research, 2019)

Table 3: Number of Owner Driven housing units in Kegalle

\begin{tabular}{|l|l|}
\hline $\begin{array}{l}\text { Divisional Secretariat } \\
\text { Division }\end{array}$ & $\begin{array}{l}\text { Number of Owner- } \\
\text { Driven housing units }\end{array}$ \\
\hline Aranayaka & 387 \\
\hline Rambukkana & 28 \\
\hline Bulathkohupitiya & 363 \\
\hline Yatiyanthota & 95 \\
\hline Deraniyagala & 43 \\
\hline Galigamuwa & 91 \\
\hline Kegalle & 170 \\
\hline Ruwanwella & 46 \\
\hline Mawanella & 89 \\
\hline Dehiowita & 149 \\
\hline Warakapola & 57 \\
\hline Total & $\mathbf{1 5 1 8}$ \\
\hline
\end{tabular}

(Source: Field research, 2019)

Out of the above-mentioned locations, the Ruwandeniya China Housing complex site was selected as the location for primary data collection since itis a donor-driven setting which constitutes a unique high rise housing structure. This is a novel set up in the Sri Lankan disaster-induced relocation context. Hence, the said location was selected to inquire into the impact of the relocation process. The Ruwandeniya China Housing complex site, also known as the China - 
Lanka friendship village has a total population of 234 with 59 housing units. Among them, 130 are females and 104 are males. All of them are Sinhala Buddhists. The highest number of females and males are 19-59 years of age and only 13 members are $0-5$ years of age, which is the lowest frequency.

Primary data collection was carried out in two phases. In the first phase, in-depth interviews were conducted with officials, and focus group interviews were carried out with community members through purposive sampling. Eight in-depth interviews were conducted with Officials from the National Building Research Organisation (NBRO), local-level administrative officials, and officials from the District Secretariat. Simultaneously, two focus group interviews were conducted with the community members with 10 members in each group. Selection of the officials was based on their expertise and the role played in the relocation process i.e. Disaster Relief Officer. On the other hand, community members were selected based on their membership in the Community Development Society. With this, the researchers got an indepth understanding of the relocation process in terms of how the relocation process was planned, involvement of the displaced communities in the process, execution of the relocation process, and grievance handling mechanisms.

Next, a community needs analysis was conducted with the participation of the same community members $(20$ members $)$ and officials (8 officials). An interview schedule was developed to conduct the needs assessment by conducting a country-specific literature review by reviewing 55 relevant publications in the context of Sri Lanka's disaster risk reduction. The said needs analysis was a great platform to understand how the relocation process has altered with the various needs of respondents. It was also a good opportunity to recognize the various needs of the displaced communities and how the said needs have changed with the process of relocation.

Given that the selected objective of the study focuses on a particular traumatic event, the said interviews and the need assessment was conducted by the co-researcher from the University of Colombo with a research team of two other trained research assistants who have experience in the field of disaster risk reduction for more than 3 years. Further, the research team has taken the necessary steps to protect the identity of the informants when presenting the data.

\section{Conceptual framework}

As the title suggests, relocation and displacements are the main two concepts of the study. The word displacement is first encountered in 
the field with the usage of the term "displaced persons" by RussianAmerican sociologist Eugene M. Kulischer (1881-1956) (Terminski, 2013). Ever since concerns were raised regarding displacement, rights of the displaced and the resettlement of the displaced are being discussed. A few initiatives which focuses on refugees, displaced and resettled communities are, the Sustainable Development Goals (20152030), the Sendai Framework for disaster risk reduction (2015-2030), the World Humanitarian Summit - 2016, the New York Declaration for Refugees and Migrants - 2016, and the Nansen Initiative on Disaster Induced Cross Border Displacement and its successor. The Centre for Poverty Analysis (2009) identifies three typologies of displacement and resettlement; namely Development Induced Displacement and Resettlement [DIDR], Conflict Induced Displacement and Resettlement [CIDR] and Natural Disaster Induced Displacement and Resettlement [NIDR]. The present study focuses on DIDR.

Discussing the Sri Lankan context of relocation, the Ministry of Defense and Urban Development defines relocation as: "Rebuilding housing, assets including productive land and public infrastructure in another location" (MODUD, 2012, Page: 4). Resettlement has been recognized as a process to assist displaced people and communities to replace their lost land, houses, assets and restore access to assets and services, and improve their socio-economic and cultural conditions. It includes the settlement of displaced people on buildable land or houses/ apartments in the same locality with barrier-free access to basic amenities. New settlement schemes in the context of development projects following restoration of law and order including restoration of livelihoods, income, and asset bases and assistance to rebuild life after being resettled, are also included in resettlement (MODUD, 2012, Page: 4).

\section{Results}

This section has been presented based on the various needs highlighted by the respondents during data collection, how they have changed due to relocation, and finally the role of the built environment in the relocation process. Therefore, the following section will comprise of a discussion on the housing needs, social-cultural needs, social infrastructural needs, economic needs, social physical needs, needs of the communities with special needs, and the role of the built environment in the relocation process.

\subsection{Housing needs}

Housing needs can be recognized as a crucial need that is affected by the relocation process. Relocation mainly revolves around the fact of 
providing new housing units for the displaced. Therefore, concerning housing needs, key thematic insights emerged with regard to the relocation process as well as the role of stakeholders. The said thematic orientations are presented as follows:

\subsubsection{Planning of the relocation process}

When considering the relocation process, it is important to understand the role played by various stakeholders. The selected donordriven relocation site has been implemented by the District Secretariat. However, the National Building Research Organization (NBRO) has coordinated the process by contributing towards the selection of a suitable site for construction. On the other hand, the overall monetary allocations were made by the Chinese Government to improve the Sri Lanka-China mutual relationship. Hence, the name of the setting is 'China friendship village'. The plan, infrastructure, and all other necessities were built according to the plan provided by the Chinese Government. Both the community members and the officials mentioned a major concern that they were not involved in designing the housing units.

"They only let us come and have a look at how they built the houses. But we didn't understand anything. It was just the foundation and a plan-we didn't understand." (Respondent C2, Community 35 years old)

The China friendship village relocation site has been constructed on two private-owned lands named Weediya Mankada Hena and Udu Wihara Thanna. These two lands were initially a cemetery that had been owned by seven different individuals. This made the land acquisition process problematic and time-consuming. According to the village main administrative officer (Garama Niladari), the land acquisition process has been carried out according to the existing legal framework related to land acquisition. According to him, a newspaper article was published regarding the acquisition as per the requirements of legal procedures and some complications occurred when two people claimed to be owners by producing deeds. Hence legally, the land is still owned by the original owners and the legal procedure is still underway. As a result, according to his projections, it will take at least 10 more years for residents to obtain deeds for their houses. 


\subsubsection{Role of National Building Research Organization (NBRO) in the relocation process}

NBRO is mainly responsible for ensuring the quality and safety of constructions in the setting. Hence, in Kegalle, after the disaster occurred it was the responsibility of NBRO to ensure that the displaced were settled in a safer place than before. The NBRO identifies areas with the below-mentioned levels of geographical risks based on their analytical studies,

- High risk

- Low risk

- Moderate risk

In the selected resettlement project, only those who were identified as living in high-risk areas received housing units. As already explained, this setting had both owner and donor-driven housing types, and the NBRO was expected to get involved in ensuring the quality and safety of housing in both housing types.

"We only assisted the selected resettlement project by selecting the land, we were not involved in making the plan of housing units" (Respondent O1 - Geologist, NBRO, Kegalle)

The respondent also mentioned that even though 16 lakhs had been provided for the land and construction of houses, it was insufficient for land with extreme slopes;

"I don't think the government has the capacity to afford more than 16 lacks per housing unit" (Respondent E1 - Geologist, NBRO, Kegalle)

Further, according to her understanding, there is insufficient land for resettlement in the Kegalle District but due to the politicization of the process, politicians do not like to send voters away from their jurisdiction due to the risk of losing votes.

According to her, another problem they face is the lack of reporting and data. Back in the 1980s and 1990s, similar disasters occurred and the victims had received housing units. But after a few generations, people had come back to their original settlement and have continued to keep the plot of land which they received as well. This is a problem that occurs as a result of not having sufficient information and data regarding previous resettlements. 


\subsubsection{Soon after displacement}

In conversation with the community, the respondents pointed out that they lived for almost 2 years in temporary camps which they found satisfying. IMO, Dialog, Red Cross, and various other NGOs have helped them and they talked about officials with gratitude. They also commended the Divisional Secretary as he was determined to resettle them before the Sinhala and Tamil New Year of 2018.

"When we were there everything was taken care of by the officials, some officers didn't even sleep at night trying to make our stay comfortable. We also received donations from people but it wasn't the government" (Respondent C1, Community 45 years old).

\subsubsection{Execution of the Relocation process} relocation:

Prior to relocation, people were given the following options for

- Resettling in a resettlement site constructed by the government (Donor-driven).

- Single storied housing unit

- Two-storied housing unit provided by the Chinese Government

- Self-Construction of houses with monetary aid provided -16 lakhs provided for construction in a given land approved by the authorities (Owner-driven).

- Building a house in their own land by providing 12 lakhs

- Buying a land of their choice and building the house through the provision of 4 lakhs for the land and 12 lakhs to build the house

Out of the above options, people in the selected settlement have selected the donor-driven option of living in a two-storied housing unit provided by the Chinese Government. Officials mentioned that they received 120 requests for the said relocation option. Even though the initial plan was to build 100 houses in the setting, only 60 houses were constructed during the first phase. Since only 60 were constructed out of the planned 100, the Chinese Government has promised the following facilities in the setting for the residents:

- A library for the children

- A playground

- A cooperative shop (A government grocery shop)

However, during primary data collection, it was evident that the above-mentioned facilities are yet to be provided to the residents. 
According to the Development Officer, the government is working on receiving the remainder of the funding to uplift the livelihoods of the residents.

Since only 60 houses were available out of 120 applicants who had selected this relocation option, only 60 families were chosen for resettlement. The first 60 families who applied were allowed to settle. However, eventually a person who had applied changed his mind and preferred to stay in the original location by giving an official statement to the authorities stating that he will not hold the government responsible if anything happens to him, his family, or their property due to any type of a natural disaster. According to the Grama Niladhari, he is a wealthy person living in a decent house and runs a business in that area. He sees this as the reason for his rejection to settle in the new relocation site.

Hence, the following local level administrative officials are utilizing that housing unit as their office:

- Grama Niladhari

- Development Officer, and

- Samurdhi officer

Once the residents were selected, they were asked to come to a place to select their house by casting lots. When selecting the houses, four families were given special attention with the consent of other residents as some members of those families belonged to vulnerable groups (Disabled).

Next, in order to hand over the house key, the residents were asked to bring their electricity meters from their original houses to the current location and fix it in their new housing unit. After this, the keys were handed over to them after a few weeks.

When deciding the eligibility of receiving a housing unit, the respondents needed to be included in the election list of the division. People who lived in the original location on rent or people who had moved out by renting out their houses in the original setting were not eligible. However, it should be noted that no need assessment was conducted before planning the relocation process.

\subsubsection{Selection of a donor-driven setting}

According to the respondents, all these people used to own at least an acre of land and houses with more than three rooms, a living room, a kitchen, and washrooms (preferably outside the house). All of them had gardens where they grew vegetables for their daily needs. Some had paddy fields where others used to work for money. They further pointed out that even though they were offered the option of building their own 
house, they were exhausted both financially and mentally to go through the process of building a new house for themselves following displacement. Hence, they preferred the donor-driven option.

"We were so tired that we couldn't think of building a new house again. We built our previous houses with so much effort and we were not fit enough to go through it again" (Respondent C3, Community 35 years old).

The community also pointed out that issues faced in temporary camps made them more frustrated when thinking of building their own houses.

"We couldn't engage in farming when we were in the camps because it was very tiring and we were very indecisive as to what we should do now" (Respondent C4, Community 35 years old)

"Camps were very hot, we spent the day time under trees. That is why we accepted this settlement, even if they offer us money to build a house now, we still can't, and we're not in a state to afford to go through that" (Respondent C5, Community 67 years old).

\subsubsection{The situation of the Original Land}

It was mentioned that settlers are allowed to go to the original setting to continue their cultivation work. However, the issue of theft and animal threats are holding them back from continuing to do so. It was also pointed out that the government is in the process of acquiring these lands as a security measure to prevent further constructions on the said land. However, the people will still be allowed to use their gardens for agricultural activities and they still have ownership of gardens. On the other hand, it was also emphasized that those who opted for the ownerdriven option were encouraged to demolish the original setting and use the material of the said house to build their new housing units.

\subsubsection{The present situation of the housing units}

None of the respondents were satisfied with the present condition of the houses mainly due to the following reasons:

\subsubsection{Housing unit as a whole}

A typical housing unit of the selected setting is 600 square feet and includes 2 bedrooms, a living room, a kitchen, and a washroom. As mentioned before, most of the respondents used to live in housing units which were bigger than the present housing unit. This tends to adversely affect the respondents' satisfaction with the current housing units. 
Another concern was that the deeds of the housing units had not been provided. However, the officials had a contrasting idea:

"I personally don't believe that we should give them a deed; we can give them a license instead. Otherwise, people will start selling these places and leaving the site" (Respondent O2 Grama Niladhari, 35 years old).

According to them, China guarantees the quality of the house for three years. If the beneficiaries have complaints, they would reconstruct the house free of charge. However, they are not confident that the Chinese Government will keep their word as they are yet to provide the above-mentioned facilities on the site.

\subsubsection{Architectural fallacies}

As per the respondents, the given housing units have the following architectural fallacies which make them regret their decision of selecting this relocation option:

\subsection{Plan of the housing unit}

As per the respondents, these houses have been designed for air conditioning. Hence, ventilation is a major concern. The respondents mentioned the inability to sleep without fans which has resulted in an escalation of electricity bills.

Other than these issues, the respondents also had a problem of not having a garden even to dump their garbage. Space which was given to them only belongs to the government and they can only grow what they like in the garden but are not allowed to do any other changes to it.

Another problem is the garbage dump which is located around $500 \mathrm{~m}$ from the area. This has caused a severe problem of pests such as flies. The respondents had to meet government officials several times to get the problem solved (through fumigation). PHIs had arrived the day before the focus group discussion was conducted and that was the first time that the officials had seen them that year.

They also mentioned another problem as the washroom was located inside houses. They prefer it outside because the two rooms were attached to the bathroom.

"Even when we want to wash our clothes, we go to the river. There's not enough space for us to do that inside the washroom. Even water costs a lot" (Respondent C7-Community, 35 years old) 
Major concerns were also raised regarding the space of the kitchen. The respondents were also dissatisfied since it had been built for gas cookers. Most of the respondents had been using firewood for cooking purposes in their previous residences and they were reluctant to switch to gas cookers due to the lack of training and the inability to financially afford gas.

\subsection{Materials used to build the housing unit}

The community further had concerns related to the materials which were used to build the housing unit. They highlighted concerns related to doors decaying with time since they had been made out of lowquality wood like Dooriyan. Mushrooms were growing on the bathroom doors and tiles were not properly fixed in the washroom which affected the safety of the residents. Having a low-quality ceiling which tends to get damaged during heavy wind was also a concern.

\subsection{Socio-cultural Needs}

The socio-cultural needs can be discussed in two particular aspects as follows:

\subsubsection{The relationship among the community members}

With regard to the ethnic fabric of the setting, it is a homogeneous community where the majority of the respondents are Sinhala Buddhists. Therefore, the respondents highlight that there are no issues with the neighbours or with other community members, they live in harmony most of the time and help each other whenever needed.

"When my mother passed away, it was my neighbours who took care of everything" (Informant C8 - Community, 45 years old). "Even if a child gets injured, all get-together and help each other" (Informant C6-Community, 32 years old).

With the above-mentioned facts, it is evident that ethnic uniformity tends to act as the glue that keeps the community together. They also have several communities and societies to help each other bond and to ensure their development. For instance, the community has formed a Death and Donation Society, Development Society, and Youth Society. As per the officials, the residents have already started working in these organizations; they have opened a Buddha statue in the site recently with the assistance of these societies.

"We can't build relationships for them; we did our job now it's their job" (Respondent O3 - GramaNiladari, 50 years old) 
The Grama Niladari also pointed out that the said communitybased organizations organize activities such as New Year celebrations, carols, and observation of sill. He also mentioned that the community tends to invite monks from temples in close proximity to temporary camps to preach on full moon (Poya) days. They also have a sewing class for women in the settlement which was organized by the Social Welfare Organization. However, the women were concerned about their children being left alone at home when they were at work.

One other reason for such harmony among the community is that the same residents had lived in temporary camps for two years. As mentioned by the respondents, during their stay in the said camps they worked as a team to rebuild their disrupted lifestyles. Hence, community relationships were at a satisfactory level among the resettled community.

One of the major concerns related to the land was that the community had been informed that the houses had been built on a cemetery. The respondents were concerned that the officials had not taken necessary steps to conduct cultural purification rituals. This has a negative impact on their cultural needs.

"One does not just build houses on land like these. They should have conducted a Bahirava Pooja and chanted Pirith before starting the constructions" (Respondent C11-Community, 45 years old).

\subsubsection{Relationship with the host community}

Even though the relationship among the community members seems to be positive, negative aspects were highlighted relating to the relationship with the host community. One of the main concerns of the host community was that they had lost the cemetery which was in close proximity to their residences due to the relocation site. Some were also concerned that the host community had been neglected when providing facilities and donations. In their opinion, the officials had prioritized the relocatees over them and this was not acceptable.

"They should have built it in another location. We have to travel for about 30 minutes to go to a cemetery now" (Respondent C12 - Community, 56 years old).

On the other hand, some of the host community members also pointed out that they had already obtained membership in community organizations that had been chartered by the residents of the relocation setting. They further said that they attend community organization meetings which are held at the community centre of the relocation setting. 


\subsection{Social- Infrastructure Needs}

The respondents are satisfied with the available social infrastructural facilities in the setting. However, with regard to education, they highlighted some concerns that they had during the transitional phase:

"Camps had places for our children to study and play, but who would study when they're surrounded by other children?" (Respondent C13 - Community, 45 years old)

"Our children couldn't do their studies properly after the disaster; even now we can't focus much on their education" (Respondent C14-Community, 34 years old).

However, the post-relocation setting has two schools which are located within $1 \mathrm{~km}$ from the site and the officials have taken the necessary steps to enrol the displaced children to nearby schools. Hence, the respondents are satisfied with the educational facilities available in the setting.

With regard to the hospitals, the respondents acknowledged that they can reach the city hospital within 20 minutes. However, they believed that it would have been better if there is, at least, a dispensary in close proximity to their residences as it would be useful for them during emergencies.

\subsection{Economic Needs}

Resettlement has directly affected the livelihoods of residents. The respondents used to be self-sufficient when they were in their original village. They did not have any additional expenses other than their minimal electricity consumption and the education of their children. But now since they do not have an outside place to cook (Dara lip) the whole cooking process has to be done using gas which is an additional cost for them.

Even though the residents still own their land in their previous villages, they are not willing to travel far to engage in farming activities in those lands. Further, if they do, someone has to stay on the farm to protect it, but they're not allowed to stay there due to security concerns.

It was also observed that women engage in the business of rolling thin cigarettes (Beedi). By rolling Beedi, they can earn an average of Sri Lankan Rupees (LKR) 500/= a day and approximately LKR.7000 a month. 
"We do this while working at home; there are days when we can't roll even a single Beedi. We're doing this because we can give our children some money to go to school at least" (Respondent C15-Community, 45 years old).

On the other hand, men who engage in daily wage labour earn approximately Rs. 2000 a day. But this is not a fixed income.

"Today is the 10th day of not getting any work" (Respondent C16 - Community, 54 years old).

On the other hand, their expenditure has also risen due to the use of electricity and water. According to the respondents, they cannot survive without earning at least Rs.10,000 a month.

"We can't go to our lands, because it costs around Rs. 400 daily to get there; that is something we can't afford. Also if we're farming, we have to keep someone to look after the crops which we're not allowed to do" (Respondent C17 - Community, 50 years old).

Due to this reason, most of the residents lost their income-earning activities leaving them poor and vulnerable consequent to relocation. They depend on daily wage labour which does not generate a stable income. According to the above respondent, there are more than ten people who get Samurdhi from the government.

\subsection{Physical- Infrastructure Needs}

The need to further improve public transportation was emphasized as the relocated community is located at a significant distance from the city centre. It was mentioned that traveling to the city centre takes more than one hour. The setting also has a community centre in which most of their community-based activities and private gatherings such as funerals and weddings take place.

It was also pointed out that the community is located near an open dumping area that needs scientific management. The open dumping area has already created issues related to health such as the spread of communicable diseases and dengue fever.

However, it was also pointed out that the setting has no recreational facilities and the residents themselves have built up a netball court for their children. Therefore, the respondents believe that it would have been better if there was at least a ground for them to gather and engage in recreational activities. 


\subsection{Communities with special needs}

As per the interviews with the officials, no specific steps have been taken to conduct programmes for communities with special needs in the setting. However, it was pointed out that the following programmes are conducted for the whole Divisional Secretariat:

- Drug awareness workshops for youth

- Counselling, financial empowerment, and recreational activities for elders

- Health workshops for pregnant mothers

- Psychological aid for displaced communities

\subsection{The role of the built environment}

In the context of the structure of governance in disaster-induced displacement, a considerable significance is placed on the built environment aspect. NBRO is the main body in the governance structure that takes the lead in land selection for relocation programmes. The officials of NBRO mentioned that they place a high level of significance on the built environment especially when they design the sites, under both owner-driven and donor-driven approaches. First, they calculate how many beneficiaries have been affected due to a disaster. Then they search for land availability for constructions. When it comes to the selection of suitable lands it was mentioned that high importance is given to the built environment. The criteria that they consider in selecting a suitable land is as follows and it is evident that they give more importance to the built environment aspect:

Table 4: Build environment aspects considered in land selection

\begin{tabular}{|l|l|}
\hline 1. & Town centre within $11 / 2 \mathrm{~km}$ \\
\hline 2. & Availability of electricity at the setting \\
\hline 3. & Availability of water at the setting \\
\hline 4. & Availability of a hospital in the close proximity \\
\hline 5. & Availability of a school in the close proximity \\
\hline
\end{tabular}

(Source: Field research, 2019)

After selecting a suitable land as per the above-mentioned criteria, they get survey plans from the AG office and make subdivision plans.

It was further mentioned that the NBRO is in the process of formulating a policy framework which will include the following aspects of the built environment in relocation settings:

- Daycare centres

- Playgrounds

- Recreational parks

- Post office 


\section{Discussion}

When reflecting upon the findings of the present study, it is evident that the relocation process in the given disaster-induced displacement setting has been formulated rapidly to offer quick relief to the displaced communities with little attention been given to the needs of the displaced communities. This is indeed a violation of the main principle of the conceptual framework of Scudder (2005). Thayer Scudder's stress and settlement process (2005) considers physiological (diseases), psychological (anxiety, depression) and socio-cultural (cultural identity) stress that people have to deal with throughout the relocation process and this could be overcome through a proper resettlement plan. The resettlement plan could be outlined in four stages: 1. Planning and recruitment, 2. Coping and adjustment, 3.Community formation and economic development, and 4.Handing over and incorporation. Hence, Scudder (2005) considers relocation to be a long term process which goes up to the extent of handing over to the next generation.

Considering this argument in the context of disasters; when disasters are a repetitive event, disaster management forms a cycle by connecting a series of interlinked activities of mitigation, preparedness, response, and recovery (Hidayat, 2010). After a disaster strikes and leaves people homeless, an important decision has to be taken in the disaster recovery phase, whether to build in the same area or to resettle the community in another area. Relocation could be considered as an option in cases of adaptation or when building in the same area is impossible (Sherbinin et al., 2011). Hence, only a well-planned and managed relocation process can produce positive, long-term development outcomes (Fernando \& Punchihewa, 2013). Fernando \& Punchihewa (2013) further have merged the concepts of relocation and displacement into several stages- before relocation, soon after relocation, sometime after relocation, and a long time after relocation. In this context, the findings reveal that most policy decisions are restricted to the planning stage of the housing setting and have not taken the long term impacts of relocation such as the economic, social, and cultural needs into consideration.

Another major drawback of the given relocation process is the lack of consultation with the displaced communities in the relocation process. Scudder (2005) and Oliver-Smith (2009) are pioneers in endorsing the aspect of consulting the displaced people as it is their living fabric that the whole displacement and relocation process tends to alter. 
Further, some of the Impoverishment risks pointed out by Cernea (2000) were visible in the selected setting. Micheal Cernea's impoverishment Risks and Reconstruction Model for resettling displaced population (2000) discusses eight possible risks that could result from the resettlement process, rather than considering different stages of relocation. These risk patterns were identified by comparing empirical studies he conducted on social integration and population displacement (Cernea, 1990). The said risks are; Landlessness, Joblessness, Homelessness, Marginalization, Food Insecurity, Increased morbidity \& Morality, Loss of access to common property and services, and Social Disarticulation. Loss of their original land and house and not having a title deed to the relocated housing unit has led them to the impoverishment risk of landlessness and homelessness. Even though Cernea (2000) has pointed out that a relocation project should endorse the risk reversal of house reconstruction and land-based reestablishment, unfortunately, that factor was missing in the selected case study. Further, the risk of joblessness was also visible as most of the respondents lost their original land- dependant livelihood strategies. However, the impoverishment risk of social disarticulation (Cernea, 2000) was not visible in the setting. As it has been already discussed, ethnic homogeneity plays a major role in binding the community together. This points out that the selected community has a strong bonding social capital. Bonding could be defined as bringing people together who are alike in important aspects such as ethnicity, age, gender, and social class (Putnam \& Gross, 2002).

This study only focuses on the two-storied housing unit based relocation setting in the Kegalle District. Hence, the findings of the present study are a key foundation to the discourse of high rise; low-density housing (Jones, 2012) for disaster-induced displaced communities.

\section{Conclusion}

In conclusion, it is important to note that the selected case study has a long way to go in adopting the existing frameworks of relocation in accepting the overall physiological, psychological, and social impacts of this long term process called relocation. On the other hand, since relocation is one of the main elements of post-disaster reconstruction of the disaster management structure, this study is a great example of why careful community-centered planning, execution, and monitoring is vital to ensure that relocation will not end up in a novel phase of a disaster. In the words of Oliver-Smith (2009); it should not be developed into another 'development disaster'. 


\section{Acknowledgments}

The REGARD project has been co-funded by the Erasmus+ Programme of the European Commission. The European Commission support for the production of this publication does not constitute an endorsement of the contents which reflects the views only of the authors, and the Commission cannot be held responsible for any use which may be made of the information contained therein.

\section{References}

1. Badri, S.A., Asgary, A., Eftekhari, A.R. and Levy, J., 2006. Postdisaster resettlement, development and change: a case study of the 1990 Manjil earthquake in Iran. Disasters, 30(4), 451-468.

2. CEPA. (2009). Forced to Move Involuntary Displacement and Resettlement - Policy and Practice. Colombo: National Library of Sri Lanka.

3. Cernea, M.M. (2000). Risks, safeguards and reconstruction: A model for population displacement and resettlement. Economic and Political Weekly, 3659-3678.

4. Cernea, M.M. (2004) October. Impoverishment risks, risk management, and reconstruction: A model of population displacement and resettlement. UN Symposium on hydropower and sustainable development (Vol. 27).

5. Fernando, N. and Punchihewa, A.G., 2013. Relocating the displaced strategies for sustainable relocation. Colombo: Friedrich Ebert Stiftung.

6. Hidayat, B. (2010) "A literature review of the role of knowledge management in post-disaster reconstruction", Salford Postgraduate Annual Research Conference (SPARC) 2010, 10-11 June 2010, Salford University, Manchester, UK.

7. International Displacement Monitoring Centre. (2018). The ripple effect: economic impacts of internal displacement.

8. Lavell, J. G. (2015). The risk of Disaster Induced Displacement in South Asia. Norwegian refugee council .

9. Ministry of Defense and urban development. (2012). Metro Colombo urban development project: social management framework. Urban Development Authority.

10. National Disaster Relief Service Centre. (2018). Statistics on natural disasters. Ministry of Disaster Management: Colombo. Available from:

http://www.ndrsc.gov.lk/web/index.php?option=com_content\&view= article\&id=61\&Itemid=69\&lang=en. [01.08.2019] 
11. Sangasumana, P. (2018). Post Disaster Relocation Issues: A Case Study of Samasarakanda Landslide in Sri Lanka. European Scientific Journal, 14(32), 1-17.

12. Scudder, T.T., 2005. The future of large dams: Dealing with social, environmental, institutional and political costs. Routledge.

13. Sherbinin, A., M. Castro, F. Gemenne, M.M. Cernea, S. Adamo, P.M. Fearnside, G. Krieger, S. Lahmani, A. Oliver-Smith, A. Pankhurst, T. Scudder, B. Singer, Y. Tan, G. Wannier, P. Boncour, C. Ehrhart, G. Hugo, B. Pandey, \& G. Shi. (2011). Preparing for resettlement associated with climate change. Science,334: 456-457.

14. Terminski, B. (2013). Development Induced Displacement and Resettlement; Theoretical Framework and current Challenges. Geneva. 